Examining the trajectories of children providing care for adults in rural Kenya Implications for service delivery

Skovdal, Morten

Published in:

Children and Youth Services Review

DOI:

10.1016/j.childyouth.2011.02.023

Publication date:

2011

Document version

Publisher's PDF, also known as Version of record

Citation for published version (APA):

Skovdal, M. (2011). Examining the trajectories of children providing care for adults in rural Kenya: Implications for service delivery. Children and Youth Services Review, 33(7), 1262-1269.

https://doi.org/10.1016/j.childyouth.2011.02.023 
Provided for non-commercial research and education use. Not for reproduction, distribution or commercial use.

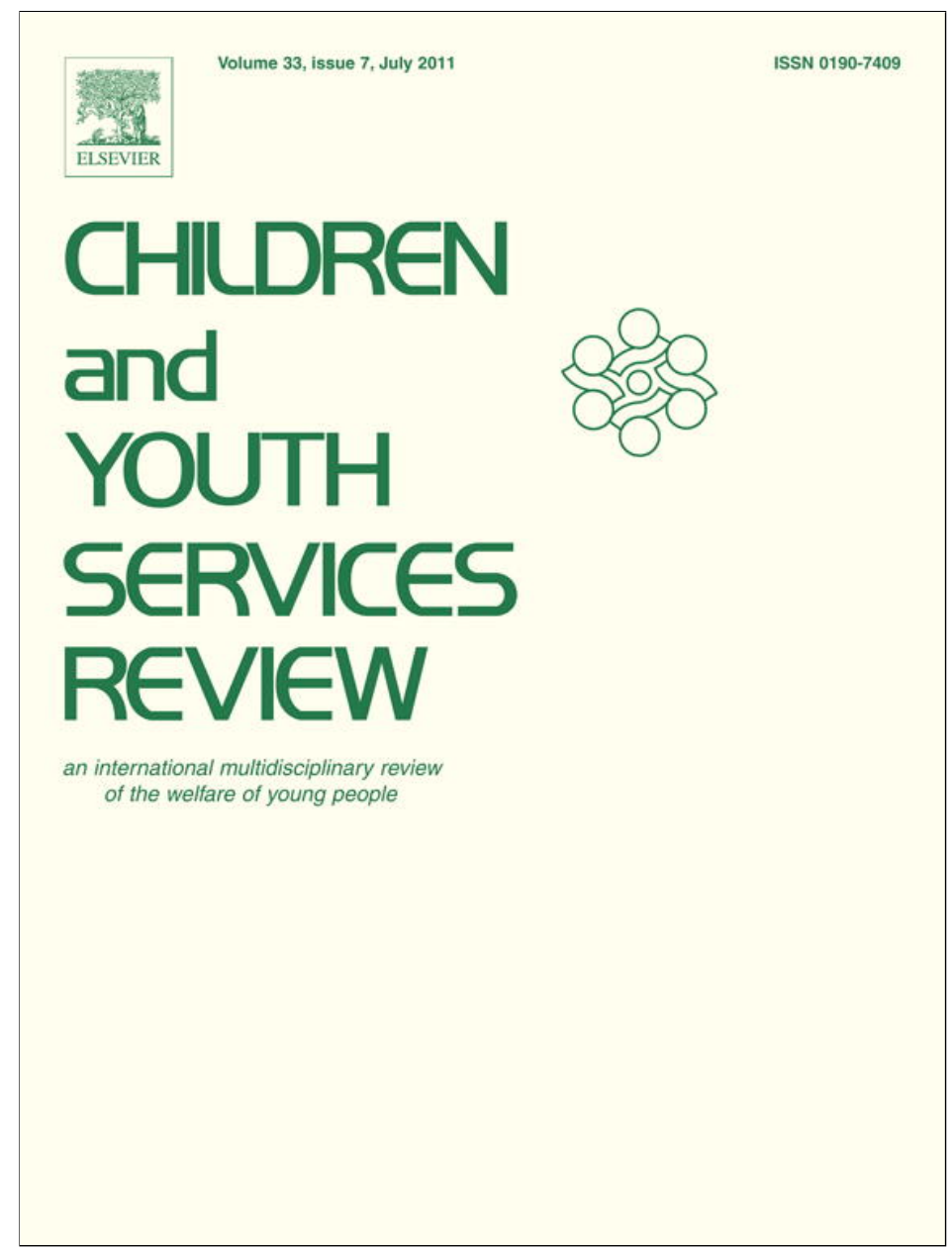

This article appeared in a journal published by Elsevier. The attached copy is furnished to the author for internal non-commercial research and education use, including for instruction at the authors institution and sharing with colleagues.

Other uses, including reproduction and distribution, or selling or licensing copies, or posting to personal, institutional or third party websites are prohibited.

In most cases authors are permitted to post their version of the article (e.g. in Word or Tex form) to their personal website or institutional repository. Authors requiring further information regarding Elsevier's archiving and manuscript policies are encouraged to visit:

http://www.elsevier.com/copyright 


\title{
Examining the trajectories of children providing care for adults in rural Kenya: Implications for service delivery
}

\author{
Morten Skovdal* \\ Institute of Social Psychology, London School of Economics and Political Science, Houghton Street, WC2A 2AE London UK
}

\section{A R T I C L E I N F O}

\section{Article history:}

Received 29 October 2010

Received in revised form 22 February 2011

Accepted 23 February 2011

Available online 27 February 2011

\section{Keywords:}

Young carers

Orphanhood

Childhood

Caregiving

HIV/AIDS

Africa

\begin{abstract}
A B S T R A C T
Research on caregiving children tends to be limited to children's caregiving experiences of parents with a specific disease or disability. This has led to a common perception that children's caregiving is a single, uniform and often long-term experience. Whilst this is most certainly the case for many children in economically more advanced countries, this may not hold true in rural Africa, where poverty and AIDS can have significant knock-on effects on entire families and communities. This paper seeks to develop a more complex understanding of children's caring experiences by asking children whom they have cared for over time and explore the different pathways that lead to their caregiving at different stages of their lives. The study reports on qualitative data collected from 48 caregiving children and 10 adults in the Bondo district of western Kenya in 2007. A multi-method approach was adapted, with historical profiles, Photovoice and drawand-write essays complementing 34 individual interviews and 2 group discussions. A thematic network analysis revealed that children's caregiving was not confined to a single experience. Children were observed to provide care for a number of different family and community members for varying periods of time and intensities. Although their living arrangements and life circumstances often gave them little choice but to care, a social recognition of children's capacity to provide care for fragile adults, helped the children construct an identity, which both children and adults drew on to rationalise children's continued and multiple caring experiences. The study concludes that agencies and community members looking to support caregiving children need to consider their care trajectories - including whom they care for as well as the order, intensity, location and duration of their past and likely future caring responsibilities.
\end{abstract}

(C) 2011 Elsevier Ltd. All rights reserved.

\section{Introduction}

In the context of AIDS and poverty, many families in sub-Saharan Africa are experiencing a steady erosion of their livelihood securities particularly those living in communities with fragile social support networks. In such families, children are at the forefront providing nursing care for their sick parents and sustaining livelihoods (Evans \& Becker, 2009; Robson, Ansell, Huber, Gould, \& van Blerk, 2006; Skovdal, 2010b; Skovdal, Ogutu, Aoro, \& Campbell, 2009). A small but growing body of literature has set out to explore the circumstances and caring scenarios of caregiving children in sub-Saharan African contexts, however a lack of longitudinal studies has meant that children's caregiving is often described statically and often limited to that of their AIDS-affected parents. Reflecting this trend, a recent literature review on caregiving children has noted that knowledge about what happens after a child has cared for a sick parent is limited (Bray, 2009). Furthermore, Evans (2010a) suggests that much can be

\footnotetext{
* Tel.: + 447738079249 .

E-mail address: m.skovdal@uwc.net.
}

learnt from research that considers the relational, intergenerational and lifecourse circumstances of caregiving children. It is against this background, and in my interest to further our understanding of how caregiving children can best be supported, that this paper seeks to explore i) whom children care for over space and time and ii) what pathways encourage children to become engaged as carers. As previous studies have highlighted who children may care for and why, this study places a deliberate emphasis on their multiple caring experiences and the need to understand their caregiving in relation to their trajectories.

The study of care is difficult due to the many factors that contribute to how caregiving is experienced by different people in different contexts. The impact of caregiving as well as the caring activities that children perform, have been found to vary according to age, illness and capabilities of the person(s) they care about and for, the presence of adult or sibling support within the household as well as the social and NGO support available to them within their context (Skovdal \& Ogutu, 2009). It is likely that the pathways into caregiving are equally complex and contextual.

In the context of AIDS in Africa, studies have reported on a range of family and community members that children may find themselves care for. These include siblings (Evans 2010b, 2010c), parents (Bauman et al., 2006; Evans \& Becker, 2009; Robson, 2000, 2004; 
E Robson \& Ansell, 2000; Robson et al., 2006; Skovdal, 2010a; Skovdal \& Ogutu, 2009; Skovdal et al., 2009), grandparents (Clacherty, 2008; RMC Evans, 2005; Skovdal, 2010b) and other community members, including young orphaned children and elderly neighbours (Abebe \& Skovdal, 2010). There are only few examples in the literature that highlight the interconnections between these care recipients, i.e. that a child may in fact care for multiple people during their childhood, indicating a continuity of care and the need to study children's caring trajectories. Evans (2010b) in a recent study on sibling-headed households in Tanzania and Uganda for example found that following their parents' death, some children decided to live on their own, free from adult domination, composing sibling-headed households. Evans (2010b) argues that sibling-headed households may be a transition from one mode of caregiving (of sick parents) to another (of younger siblings). On the other hand, Clacherty (2008) in Tanzania found children, after their parents had died, to move in with their elderly grandparents where they resumed caregiving. A Save the Children (2010) report also notes, as one of the first issues emerging from their four country study, that children had multiple and repeated caring experiences. This paper seeks to expand on these early observations, albeit in a Kenyan context and is a direct response to Evans (2010a) call for further research into children's changing caring roles and trajectories over time, space and between generations.

\section{Towards a trajectory model of young caregiving}

To develop effective support strategies for caregiving children, service delivery organisations need to understand the relationship between children's living arrangements, life circumstances and children's varied motivations and pathways to caregiving. One important first step to conceptualise variance in young caregiving was done by Becker (2007) who suggested the need for a continuum on which children's caregiving responsibilities can be located. On this continuum all children's caregiving activities can be located, with the majority of children found at one end of the continuum, providing low levels of caregiving and having little responsibility in sustaining household livelihoods. Caregiving children on the other hand would be located at the 'high' end of the continuum with substantial, regular and significant caregiving responsibilities (see also Evans, 2010a; Evans \& Becker, 2009). While this conceptualisation is useful to discuss the extent of children's involvement in care work (i.e. the intensity of their caregiving), it does not capture adequately the changes that occur to the life of a caregiving child over time. Caregiving children should not be statically located on a continuum; they should be seen to constantly move along a continuum with changing and repeating caregiving roles and intensities. This paper argues that locating caregiving children within trajectories of care, influenced by life circumstances and changing living arrangements, will provide a more complex understanding and acknowledgement of the series of care roles that children may have over time and space with fluctuating intensities. By locating caregiving children within trajectories of care, service delivery organisations will be better equipped to provide services that consider changes to a child's caring roles and is better able to address the unique needs of each child. Developing a trajectory model of young caregiving would encourage practitioners to look beyond children's current caring role, allowing them to predict, plan and manage support for caregiving children in ways that are relevant to their contextual circumstances.

\section{Methodology}

\subsection{Study area and participants}

The paper reports on findings from a study conducted in the rural district of Bondo in Western Kenya, a district predominantly inhabited by the Luo ethnic tribe. The district neighbours Lake Victoria and is characterised by high levels of HIV, poverty and a poor infrastructure
(GOK, 2006). The fishing industry and seasonal migration patterns have contributed to the rapid spread of HIV. Even with a conservative estimate of $13.7 \%$, the HIV prevalence rate is still twice the national average (NACC, 2006). Many children in the district are experiencing the consequences of HIV/AIDS. It has been estimated that one in three children in the district have lost one or both parents (Nyambedha, Wandibba, \& Aagaard-Hansen, 2003). Study participants were recruited from the vicinity of two rural community-based organisations by its leaders. The leaders were encouraged to identify children with diverse caring experiences and an equal number of boys and girls. A total of 48 caregiving children between 12 and 17 and 10 adult care-receivers (mix of parents or elderly guardians) from the community agreed to participate in this qualitative study.

\subsection{Data collection and analysis}

To recognise and support the variety of ways in which children feel most able to share their experiences and perceptions of a phenomenon, in this case young caregiving, a multi-method approach was adopted (Brewer \& Hunter, 1989; O'Kane, 2008). As detailed in Table 1, the methods used with the children included history profiles, drawing and essay writing (Rifkin \& Pridmore, 2001), Photovoice ${ }^{1}$ (Wang, 2006; Wang \& Burris, 1997) as well as individual interviews and group discussions (Flick, 2002). Adults were interviewed individually. As Table 1 also illustrates, not all the children were interviewed individually or wrote essays on young caregiving. Children that were interviewed or wrote essays on their experiences of caregiving did so because they showed interest and had a diverse set of experiences. The data was gathered in Dholuo language by two local research assistants.

All written essays, historical profiles, interviews and group discussions were transcribed and translated from Dholuo into English. All written and transcribed material was read and re-read before being imported into Atlas.Ti - a qualitative data analysis software package for a thematic network analysis (Attride-Stirling, 2001). To uncover implicit social meanings and processes, explicit statements made by the informants were questioned and reflected upon in relation to the wider material. Topics emerging from the analysis were coded, accompanied with notes detailing the issues being discussed as well as contradictions. To examine children's multiple caring experiences, this paper draws on 17 such codes, or basic themes, which have been organised into higherorder themes that highlight who children care for and why they care (see Table 2). Table 2 also illustrates the structure of the discussion of findings. Other emerging themes have been reported on elsewhere and include reciprocity of care (Skovdal, 2010b), their coping strategies (Skovdal et al., 2009), resilience building (Skovdal \& Andreouli, 2010), psychosocial wellbeing (Skovdal \& Ogutu, 2009) and their experiences of participating in a microfinance initiative (Skovdal, 2010c).

The study received approval from the Research Ethics Committee of the London School of Economics, as well as the Department for Gender, Children and Social Development in Kenya. On agreement that confidentiality would be ensured, informed and written consent was obtained from all participants and their guardians. Fictitious names have therefore been used in the presentation of findings.

\section{Findings}

\subsection{Who do children care for?}

- their sick parents

All the children participating in this study had at some point in their lives provided care for their sick parents. In 2003, at the age of 10 , Beryl lost both her father and a younger sibling to AIDS, both

\footnotetext{
${ }^{1}$ Photovoice is a process whereby children can explore, enhance and communicate circumstances in their lives through photos they have taken and written about.
} 
Table 1

Data collection procedure.

\begin{tabular}{|c|c|c|c|c|c|}
\hline Steps & Date & Who & $\mathrm{N}$ & Methods & Sampling \\
\hline 1 & June 2007 & Caregiving children & 48 & History profiles & Recruited purposively through local community guides \\
\hline 2 & July 2007 & Caregiving children & 48 & Photovoice, drawing and essay writing & Recruited purposively through local community guides \\
\hline 3 & July 2007 & Caregiving children & 27 & Essay on caregiving & All participating children invited \\
\hline 4 & July/Aug. 2007 & Caregiving children & 24 & In-depth interviews & $\begin{array}{l}\text { Selected to represent diversity of responses on Photovoice and } \\
\text { willingness to participate }\end{array}$ \\
\hline 5 & Sept./Oct. 2007 & Caregiving children & 33 & 2 group discussions & All participating children invited \\
\hline 6 & Sept./Oct. 2007 & Adults & 10 & In-depth interviews & Purposively to include lay people and social development professionals \\
\hline
\end{tabular}

of whom required significant nursing care before their passing. Although initially Beryl was not the only household member involved in caregiving; her two mothers were initially helping her but also got sick during this period, intensifying Beryl's caring responsibilities. Beryl's older mother (her father's first wife) died in 2005, leaving Beryl alone with her biological mother who passed away shortly after she wrote this essay about caring for her.

"My mother got sick, but it was not all that serious in the beginning, however the sickness persisted, I started taking her to the hospital, I looked for food whilst I was also going to school. I had to ensure that I left school early to look into ways of getting flour. Now she is worse, I wash her; I look for food, fetch water. I cook and feed her and take her to the bed. In the morning I wake up very early, around $3 \mathrm{am}$, help her go to the latrine and prepare for her breakfast and fetch water. Before going to school I give her drugs and breakfast. I go to school until around $4.00 \mathrm{pm}$, when I come back I usually find she has helped herself [defecated] in the bed and I have to clean her and wash the bedding." Beryl, 14 (essay)

Beryl's experiences illustrate the devastating impact AIDS can have on families as they experience numerous successive deaths and how children of such families rarely just care for one parent during their life time. As the disease took stronghold, reducing the number of active adult members within her household, Beryl's caring responsibilities intensified.

\section{- their grandparents}

Like many orphaned children, Beryl now lives with her grandmother. However, the fragility of many grandparents who often struggle to adequately support orphaned children under their foster care, as well as themselves, results in children continuing their caregiving role.

"I took a photo of my grandmother whom I am taking care of. She is sick up to now and she can't be alone for many hours. I ensure she gets what she needs. I also ensure that water is in the house, wash it, wash her clothes, utensils, cook and give it to her." Syprose, 14 (photovoice)

One elderly guardian of a caregiving child explains how useful and normal it is for lone grandparents to have a grandchild taking care of them.

"Maybe somebody is old and therefore doesn't have many relatives to care for him or her, but he or she is blessed with a

Table 2

Global theme: the circumstances and perceptions surrounding caregiving children.

\begin{tabular}{|c|c|c|c|}
\hline Global Themes & Organising Themes & Issues discussed & Basic Themes/Codes \\
\hline \multirow[t]{5}{*}{ Care recipients } & $\begin{array}{l}\text { 1. Many children provide care and support } \\
\text { for ailing parents. }\end{array}$ & $\begin{array}{l}\text { - Nursing duties } \\
\text { - Head-of-household } \\
\text { - Symptoms }\end{array}$ & $\begin{array}{l}\text { - Sick parents/guardians } \\
\text { ( } 36 \text { children, } 2 \text { adults) }\end{array}$ \\
\hline & $\begin{array}{l}\text { 2. Many children provide care and support } \\
\text { for elderly people. }\end{array}$ & $\begin{array}{l}\text { - Old age inabilities } \\
\text { - Fetching of water and firewood } \\
\text { - As children of the elderly die of AIDS, } \\
\text { grandchildren need to take care }\end{array}$ & $\begin{array}{l}\text { - Caring for grandparents } \\
\text { ( } 45 \text { children, } 8 \text { adults) }\end{array}$ \\
\hline & $\begin{array}{l}\text { 3. Many children provide care and support } \\
\text { for siblings }\end{array}$ & $\begin{array}{l}\text { - Younger siblings } \\
\text { - Sick siblings }\end{array}$ & - Caring for siblings (10 children) \\
\hline & $\begin{array}{l}\text { 4. Some children provide care for abandoned } \\
\text { community members }\end{array}$ & $\begin{array}{l}\text { - Abandoned neighbours } \\
\text { - Orphaned children }\end{array}$ & $\begin{array}{l}\text { - Caring for community elders } \\
\text { ( } 6 \text { children) } \\
\text { - Caring for orphaned children } \\
\text { ( } 3 \text { children) }\end{array}$ \\
\hline & $\begin{array}{l}\text { 5. Children care for multiple people over } \\
\text { time and space }\end{array}$ & $\begin{array}{l}\text { - One caregiving experience often leads } \\
\text { to another }\end{array}$ & \\
\hline \multirow[t]{9}{*}{ Pathways to young caregiving } & 6. AIDS is often a cause of caregiving. & - Successive deaths of family members & $\begin{array}{l}\text { - Disease and family background } \\
\text { (26 children, } 1 \text { adult) }\end{array}$ \\
\hline & \multirow{3}{*}{$\begin{array}{l}\text { 7. There are socio-cultural reasons to why } \\
\text { children are likely to engage in young } \\
\text { caregiving and occasionally sent away } \\
\text { to do so. }\end{array}$} & $\begin{array}{l}\text { - Stigma } \\
\text { - Symptoms and weakness }\end{array}$ & - HIV/AIDS (9 children, 3 adults) \\
\hline & & - Restrictions on who can care for who & $\begin{array}{l}\text { - Cultural traditions impact } \\
\text { ( } 14 \text { children, } 9 \text { adults) }\end{array}$ \\
\hline & & $\begin{array}{l}\text { - Adult/child customs } \\
\text { - Gender } \\
\text { - Migration }\end{array}$ & - Sent to care ( 10 children, 2 adults) \\
\hline & $\begin{array}{l}\text { 8. Caregiving children may come from } \\
\text { families with limited social support } \\
\text { and where there is nobody else to provide care. }\end{array}$ & $\begin{array}{l}\text { - Poverty related struggles } \\
\text { - Disease } \\
\text { - Accidents }\end{array}$ & $\begin{array}{l}\text { - Family circumstances } \\
\text { ( } 8 \text { children) } \\
\text { - Lack of support ( } 11 \text { children) } \\
\text { - Need additional support } \\
\text { ( } 3 \text { children, } 2 \text { adults) }\end{array}$ \\
\hline & \multirow{4}{*}{$\begin{array}{l}\text { 9. Many children want to provide care and } \\
\text { support - often driven by reciprocity, } \\
\text { future support and social recognition. }\end{array}$} & - No one else to do it & - Poverty ( 23 children, 8 adults) \\
\hline & & $\begin{array}{l}\text { - Struggles } \\
\text { - Always support the needy }\end{array}$ & $\begin{array}{l}\text { - Commitment to provide } \\
\text { care/support ( } 5 \text { children) }\end{array}$ \\
\hline & & - Love for the vulnerable & - Felt need to act (15 children) \\
\hline & & - Reciprocating care and support & $\begin{array}{l}\text { - Reciprocity ( } 19 \text { children) } \\
\text { - Strategic caregiving ( } 20 \text { children) }\end{array}$ \\
\hline
\end{tabular}


grandchild, the grandchild will take care of the old grandparent." Grace, guardian (interview)

This local expectation of children taking care of grandparents can result in children being sent away to care from a very young age.

\section{- their siblings}

It is common for older children to assist their parents with child care. However, sometimes their caregiving of siblings extend above and beyond what is ordinarily expected, particularly if their sibling is sick or disabled. Describing a photo of heaven, 13-year-old Salome speaks about his second caregiving experience after his father, namely that of his sister.

"I want to talk about my sister's illness from when it started to the time she died to rest in Heaven. My sister started to get sick little by little and she was sleeping most of the time unable to do anything. She got weaker and weaker and this was at a time when my mother had gone to bury her father. I had no choice but to stay at home and be with her and feed her like as if she was a little child. She could not eat by herself and could only eat very small portions. When I finally noticed that she could eat something, I gained some strength. I was washing her, washing her clothes and I gave her drugs within the correct intervals. I also cooked for her. I couldn't move away from her and applied oil to her body." Salome, 13 (Photovoice)

\section{- abandoned community members}

In addition to providing care for immediate or extended family members, a few children also spoke about their caregiving of fellow community members. Seventeen-year-old Jane, for example, who cared for her mother until her death and now lives with and care for her elderly grandmother, describes how she has taken into her care an orphaned boy who had nowhere else to go.

"The child is left alone; no one is there to help this child with food, except from me. I took a photo a child because I help him in certain ways. I love him and assist him by washing his body, giving him food, buying him clothes if I have enough money and play with him to make him happy so that he doesn't think of the situation of his parents. He sleeps in my room and I wash his clothes." Jane, 17 (Photovoice)

Similarly, 13-year-old Samuel reports on his experiences of taking care of an ageing neighbour. Samuel emphasises that nobody else was there to care for him and therefore feels a sense of duty. Samuel's willingness to care for his older neighbour may be encouraged by his respect and sympathy for older people, but also the power of being able to keep someone well and alive.
"I want to talk about this old man because has lost all his children and I was his neighbour and the one who cared for him. I took him out as he couldn't walk and took him back to the house, cooked for him and gave him food. I was helping this man until his death. I was fetching water, firewood and cleaned him and his house. I was caring for him as he was too old to do anything." Samuel, 13 (draw-and-write)

Samuel's experiences of caring for a neighbour challenge any assumptions that caregiving children need to live with the person they care for. This suggests a need to make a distinction between coresident and visiting caregivers. Visiting caregivers may provide care of own free will and can more easily 'escape' from their caregiving responsibilities at the end of the day.

- many different people

However, for many of the children, caring was not constrained to one individual and one experience, but a role that was recognised and seen as transferable to different people needing care.

"I have provided care for many people. In fact, I have been caring for children, my parents, grandparents, relatives and many other people. In our village, I'm caring for the aged by fetching water, firewood and washing their clothes. I sometimes cook for them." Carren, 17 (essay)

The historical profiles written by the children (see Figs. 1 and 2 for examples) illustrate well that children's caregiving is not a single experience, but that they may find themselves care for different people at different points in their lives - partly as a result of the changing caring needs of family members.

Although the children participating in this study were recruited because they, at some point recently, had provided significant nursing care and support for a sick parent, it transpired that this group of children had also cared for numerous other less able bodied people, including younger siblings, grand parents and community members. Caregiving children can therefore find themselves caring for different people and taking on multiple caring roles over time.

In presenting who the children care for, insights into some of their roles and responsibilities were also revealed. To understand why children care and typically have multiple caring experiences, the next section seeks to highlight some of the pathways to young caregiving.

\subsection{Why do children care?}

- because of AIDS

AIDS is arguably the root cause of much young caregiving in Africa. Although the children rarely mentioned, or know that it is AIDS which has caused their parents to be ill, the accounts and history profiles

1992: I was born in Bondo Hospital

1994: I started nursery school and was there until standard three.

1999: I helped caring for my father who died when I was in standard three.

2000: My mother became ill when I was in class four. I left school to care for my mother until she was admitted to the hospital where she died.

2002: After my mother's death and burial I went back to school.

2004: My grandmother passed away and my other grandmother told me to leave school to stay with her, but I refused.

2005: I left home to live with mother's sister whom I am living with up to now.

2006: When I was in class six, my aunt told me that I should go and care for my grandmother.

Fig. 1. Abridged history profile of Carolyn, age 15. 
1991: I started school, but my father died and I had to leave school.

1992: I was out of school.

1993: I was caring for my siblings.

1994: My mother left for Asembo, so we were left alone at our home.

1995: My mother came back seriously sick. I cared for her.

1996: My mother was healed and I went back to school

1998-05: I am still in school.

2007: I am in school, in class five and I am now living with my elderly grandmother and help her with day-to-day chores.

2007: I joined a programme

Fig. 2. Abridged history profile of Susan, age 13 .

produced by the children do suggest that AIDS, or symptoms related to the treatment of AIDS, is what makes them fragile.

"My father's hands started swelling, this continued and the hands got very big. I was always the one caring for him. I was washing the feet, the swollen legs, giving drugs and by then my mother was also sick. His hands were all swollen and so I was pressing this stuff out of the swollen hands, used dressing and put drugs on the legs, prepared his food, spoon fed him as he could not eat by himself because of the sores all over his body." Samuel, 13 (interview)

\section{- for socio-cultural reasons}

Childhood in this context is seen as a time where children actively participate in community life and obtain life skills through duty and service to their household and community. With limited social protection schemes and often inadequate health services, this rural community continues to embrace children's social role as 'helpers', seeing them as a valuable resource in the care and support of vulnerable family members. This was illustrated through the many experiences of children being 'sent to care'.

"The children can help in various ways, they can assist the grandmother to get what she needs, prepare porridge, wash her clothes etc. If I go and see that she is in a serious condition, when I come back, I send my child and instruct him/her to help with whatever things she need. If the sons and their wives don't help the grandmother, their daughters will send their children to help out." Jacky, guardian (interview)

"My grandmother had a problem and I was sent here to stay with her. Her leg has a big wound. She was trying to get by, but couldn't and that is why I came here, to help her." Jane, 17 (Photovoice)

Not only were children sent to care for their elderly grandparents, they could also be sent to care for elderly community members who, because of AIDS, stigma and poverty, had no family members able/ willing to help them.

"She [A neighbour] only has one daughter and since the daughter refused to take care of her, she came to my mother and asked for permission to allow me to stay with her and help her out." Jane, 17 (interview)

Although the children would typically only be 'sent to care' for a year at a time (although sometimes longer), this came at a considerable cost to many children who were forced to leave their school, friends and family temporarily. Whilst some children got the opportunity to attend school in their new location, many did not and therefore had an involuntary break from school. The decision as to which child to send was often rooted in socio-cultural and gendered constructions of care. A girl child who is not in secondary school (which is seen as an investment) and with previous caregiving experiences seemed to take preference.

Also related to gender are examples of when female adults (who are typically the first source of caregiving) are around, and who in principle could help out with the caregiving, are unable to do so because of social and cultural factors. Zeddy gives an example of how his grandmother cannot assist with some caregiving duties, because Luo tradition does not allow a mother to enter the bedroom of her adult son.

"I cared for my father when he was seriously sick; I could not go to school for a year since there was no other person at home. Since my father was bedridden in his bedroom, my grandmother could not help as she cannot enter his room. This made me not to go to school for a year. My grandmother could prepare food for him but could not give him since he was in the bedroom; so I was the one giving him food, spoon feeding him." Zeddy, 16 (essay)

\section{- because there is nobody else to provide care}

A combination of poverty and the absence of biological and foster parents to facilitate the care of those who were sick or frail meant that many children had to take matters in their own hands. Seventeen-yearold Carren for example, who cares for her younger siblings, sees no other way but to work to cover their needs and does so gladly.

"I enjoy looking after my younger siblings; I wash them, play with them and sell firewood, cut wood for burning charcoal, because it is the only way to cover our needs." Carren, 17 (interview)

Likewise, Jael, a 14-year-old girl, found herself as the only one available to do the caring.

"Our mother had been sick for a while and I was the one was caring for her as there was no one else to care for her." Jael, 14 (draw-andwrite)

\section{- because they want to}

So far I have outlined some of the social factors that contribute to children engaging as carers. The second half of this subsection will look at some of the psychosocial factors that encourage children to provide care, including a social recognition of their efforts and reciprocity of caregiving. Earlier I mentioned that childhood in this context is characterised as a period of duty and service. As such, children who live up to these expectations and perhaps go beyond what would normally be expected of them are socially recognised for their extraordinary contribution to community life.

"My life differs with that of other children in the community on what do and how I handle things; I am saved, both in actions and 
deeds, I work differently, I don't mind carrying firewood bundles on my head to the market to sell and I enjoy doing it, others don't want to carry, they feel ashamed to do this. So my life differs due the things I do." Rebecca, 15 (interview)

As illustrated by Rebecca, this recognition can provide some children with a motivation and interest to be caregivers, contributing to the development of a positive caregiver identity. This identity can motivate some children, as indeed highlighted by some of the quotations so far, to care voluntarily and go from one caregiving experience to the next. Also religion and faith contributes to a recognition of their efforts. Caregiving is intrinsically linked with 'doing good' in God's eyes and a number of children drew on this recognition of their efforts as an incentive to care.

"It is my personal view, that if I care for a sick person, I'm happy since I get blessings from God because it is not good for someone to suffer while you are there." Samuel, 13 (interview)

"By helping the needy we are also blessed by God for our help." Michael, 15 (Photovoice)

Depending on the severity of the household situation, many children happily help out their parents due to the strong bond of love that exists between them. This is illustrated by 14-year-old Pascal who cares for his father.

"Because I love my father so much, I choose to be with him and help him out." Pascal, 14 (interview)

Pascal's wish to care for his father reflects the emotional bond between them - a bond which can take different forms depending on the child's circumstances and is often rooted in reciprocity of care. Many children felt they owed their parents something for the love and upbringing they have been given. Many caregiving children therefore wanted to reciprocate the caring they once received from their parents.

"What encourages me to take care of my mother is that she was the one who gave birth to me, she brought me up and also cared for me, I did not see any reason of neglecting her, I have to assist her in problems, I love my mother." Francis, 14 (interview)

Reciprocity of care was not only evident amongst children living with their biological parents, but also amongst children living with foster parents where the emotional attachment may still be developing. But children, like 15-year-old Sharon, recognise the care and support they have received from their foster parents and take the opportunity to reciprocate care.

"I took a picture of a woman because it reminds me of the help I have given this woman and how she has helped me. I remember everything she has done to me, from my childhood to now. I was once unable, now she is unable." Sharon, 15 (Photovoice)

Children being sent to care for family and community members whom they had not received care from before did not draw on reciprocity of care in the same way. Instead, the children sent to care saw caregiving as an opportunity to be seen as 'helpers', an identity and role that can earn them respect and support.

"I use my talent to help others and I use it wisely, God also feels happy. Sometimes I also get gifts from others when I help them. Some give me gifts like clothes and food when they can afford. Helping the needy has really improved my life." Michael, 15 (Photovoice)

\section{Discussion}

To develop a more complex understanding of children's caring trajectories, this paper sought to explore who children care for over time and space and the different pathways that lead to their caregiving. Behind the seemingly simple questions of who children care for and why emerges very complex caring trajectories, resulting from changing living arrangements and life circumstances. Unlike their counterparts in economically more advanced countries, caregiving experienced by children in rural Kenya was rarely restricted to a single family member and a one-off experience. Children in this context were found to perform a series of caring roles for multiple family and community members over the course of their childhood.

The findings presented in this paper allude to a possible pattern of common and likely trajectories, linking children's living arrangements and life circumstances together with whom they are caring for. This pattern is illustrated in Fig. 3 and highlight that children's first caregiving experiences tend to be of younger siblings (e.g. by helping parents with child care) or elderly grandparents or sick neighbours (e.g. by being sent to care for them by their parents, reflecting the social role of children). If the parents are living with HIV and develop HIV and AIDS-related illnesses, children are likely to provide quite significant nursing care and take responsibility for sustaining their household. However, depending on their living arrangements, the intensity of responsibilities are likely to fluctuate and should be understood against the continuum of young caregiving (cf. Becker, 2007; Evans \& Becker, 2009). If the children experience parental bereavement, their new living arrangements will determine the course of their caring trajectory. Depending on the age of the children, they may be collected by family members and taken into foster care or they may decide themselves whom they want to stay with - if anyone. Reflecting the findings of this study, children either moved in with sick or elderly guardians, who were community members, more distant relatives or their grandparents (See also Clacherty, 2008) or decided to stay on their own without adult supervision. If the children move in with healthy aunts and uncles who treat the orphaned children as their own, then this may be the end of their caregiving. However, as the children participating in this study were providing care at the time of the study, they did not fall within this category. The fact that many orphaned children are absorbed into already vulnerable households, highlight, in the context of limited social and health services, the important role of children in assisting the most vulnerable.

It is important that the pattern described in Fig. 3 is not taken literally as children can take on caregiving roles for any family member or neighbour in any order and at any time and location. The fact that children's care and living arrangements are not fixed has been identified

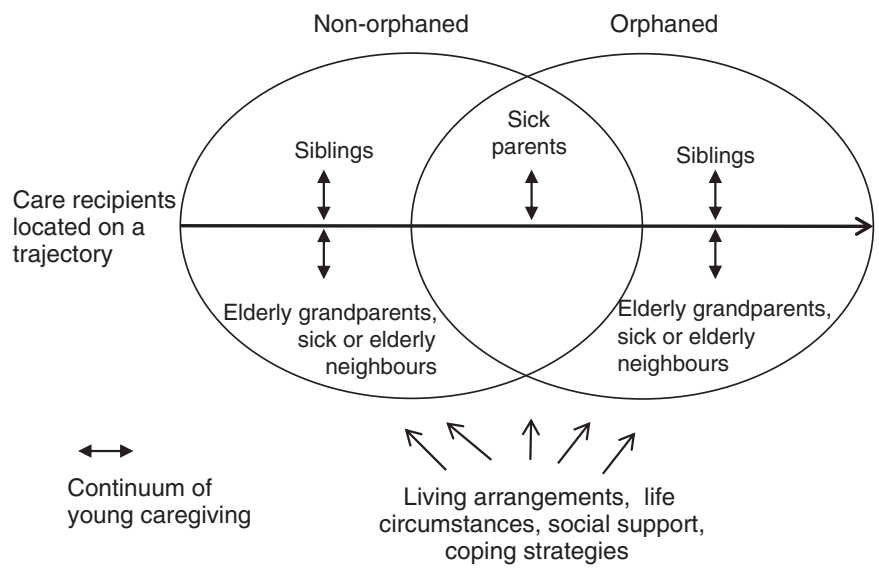

Fig. 3. Simplified model of possible care trajectories. 
by Evans (2010b) who in her study of sibling-headed households in Tanzania and Uganda, found that children who may initially be absorbed by family and community members, may find it difficult to live there and therefore choose to live on their own in sibling-headed households where they can care for each other. Equally, children may initially decide to stay on their own, but find it difficult and therefore choose to move in with elderly or sick family or community members. Despite this complexity, the pattern described in Fig. 3 provides a platform for researchers and practitioners to begin to think about children's caregiving within a trajectory of care that is dependent on the children's living arrangements and life circumstances. Future research should explore children's care trajectories further and uncover areas of particular vulnerability and explore ways in which practitioners can use a trajectory framework to plan and manage support for caregiving children. Furthermore, what has been absent from this paper is an account of how children of different age groups and developmental capabilities as well as the composition of sibling groups contribute to the different experiences of caregiving and influence a child's caring trajectory.

Through the examination of children's trajectories of care, a number of interesting issues emerged. The issue of gender deserve some discussion. Although poverty and disease may contribute to some families ignoring sociocultural constructions of gender, as illustrated by some families' strategic decision to socialise boys to know 'female duties' in preparation for the possible premature death of their future wives (Skovdal et al., 2009), findings presented in this paper suggest many families are still guided by gendered constructions of care. Girls were far more likely to be sent away to care. Other studies in sub-Saharan Africa have highlighted the increased likelihood of girls engaging in care (Evans \& Thomas, 2009; Robson, 2000; Robson \& Ansell, 2000) as well as observed the perception that boys should not do certain duties (Robson et al., 2006).

The observation of children being 'sent to care' has previously been discussed in a Tanzanian context in relation to how families affected by AIDS use their social networks and family ties to cope with poverty and disease (Evans, 2005). Children in this study were 'sent to care' for relatives far afield and for neighbours. The impacts of these caring scenarios are likely to be very different and suggest that the model of children's care trajectories need also to consider the different scenarios of non-resident caregiving children (e.g. the ones who care for a nearby community member) and those in co-residence who have been uprooted from their school environment and social networks to migrate to a different location in order to provide care for a fragile adult. Although the caring responsibilities may be similar, their social contexts differ significantly and are likely to play a key role in how the children cope with their circumstances (Skovdal et al., 2009).

Finally, the findings also suggest that children's caregiving experiences are embedded within a complex web of social expectations, reciprocity of care, love for their parents and a social recognition of their caregiving responsibilities. This web can encourage some children to see caregiving as a 'career' - something they take pride in and willingly do for people in need of care (see also Skovdal \& Andreouli, 2010). Although many children find themselves caring because of a lack of alternatives in contexts of poverty and limited social support (Evans, 2010a) one should not assume that children's caregiving is always a chore and burden. Children are able to negotiate positive meanings from desperate situations, giving them a sense of control. They primarily did this through a social recognition of their caregiving and also through Christian values, as has been observed in Zimbabwe (Robson \& Ansell, 2000). Drawing on a social recognition of their responsibilities and capacity to care for fragile adults, helped some caregiving children construct an identity, which both children and adults drew on to rationalise children's continued and multiple caring experiences. The emotional attachment that seemed to guide some children's decision to care has also been observed by Evans and Thomas (2009) through their work with caregivers in UK, Namibia and Tanzania. They paint a complex picture of conflicting emotions, which although rooted in empathy and love, can cause tensions that may undermine the wellbeing of both the carer and the care recipient.

The study has got certain limitations that deserve mentioning. The children's participation in the study was entirely voluntary and required a fair amount of their time. As such, this study only draws on the views of children who wanted to share their circumstances and had time and energy to participate. The views of children who were so busy and burdened by their caregiving responsibilities that they could not participate have therefore not be included. One outcome of this limitation may be that children participating in this study are not the most vulnerable caregiving children.

\section{Implications for policy and practise}

This exploratory study has presented a complex picture of children's pathways to caregiving. By locating caregiving children within trajectories of care, the study has opened up opportunities to explore caregiving children's needs, vulnerabilities, coping strategies and resilience in relation to whom they care for, or have previously cared for and the order, intensity, location and duration of their caring experiences. Such a framework considers the changing living arrangements and life circumstances of caregiving children, and acknowledges the different impacts this may have on the intensity of their duties and the levels of support available to them. Support for caregiving children is therefore best provided against an appreciation of the social circumstances that lead to children's multiple and changing caring roles over time and space.

\section{References}

Abebe, T., \& Skovdal, M. (2010). Livelihoods, care and the familial relations of AIDS affected children in eastern Africa AIDS Care, iFirst. http://dx.doi.org/10.1080/ 09540120903311474

Attride-Stirling, J. (2001). Thematic networks: An analytic tool for qualitative research. Qualitative Research, 1(3), 385-405.

Bauman, L., Foster, G., Silver, E., Berman, R., Gamble, I., \& Muchaneta, L. (2006). Children caring for their ill parents with HIV/AIDS. Vulnerable Children and Youth Studies, 1(1), $56-70$.

Becker, S. (2007). Global perspectives on children's unpaid caregiving in the family: Research and policy on 'young carers' in the UK, Australia, the USA and Sub-Saharan Africa. Global Social Policy, 7(1), 23-50.

Bray, R. (2009). A literature reveiw on child carers in Angloa, Nigeria, Uganda and Zimbabwe. Pretoria, South Africa: Save the Children UK/South Africa. retrieved from. http://www.crin.org/docs/SCUK_lit_review.pdf on 04/10/2010.

Brewer, J., \& Hunter, A. (1989). Multimethod research: A synthesis of styles. Newbury Park, Ca.: Sage Publications.

Clacherty, G. (2008). Living with our Bibi: 'Our granny is always our hope' - A qualitative study of children living with grandmothers in the Nshamba area of north western Tanzania. retrived from. http://www.helpage.de/material/Living_with.pdf (04/10/2010): World Vision/REPSSI.

Evans, R. (2005). Social networks, migration, and care in Tanzania - Caregivers' and children's resilience to coping with HIV/AIDS. Journal of Children and Poverty, 11(2), $111-129$.

Evans, R. (2010a). Children's caring roles and responsibilities within the family in Africa. Geography Compass, 10(4), 1477-1496.

Evans, R. (2010b). The experiences and priorities of young people who care for their siblings in Tanzania and Uganda: School of Human and Environmental Sciences, University of Reading. Retrieved from. http://www.crin.org/docs/Sibling\%20Caregivers_Evans.pdf 04/10/2010.

Evans, R. (2010c). We are managing our own lives...": Life transitions and care in siblingheaded households affected by AIDS in Tanzania and Uganda. Area, doi:10.1111 j.1475-4762.2010.00954.x.

Evans, R., \& Becker, S. (2009). Children caring for parents with HIV and AIDS: Global issues and policy responses. Bristol: Policy Press.

Evans, R., \& Thomas, F. (2009). Emotional interactions and an ethics of care: Caring relations in families affected by HIV and AIDS. Emotion, Space and Society, 2(2), $111-119$.

Flick, U. (2002). An introduction to qualitative research (2nd ed.). London: SAGE.

GOK (2006). Bondo District Annual Monitoring and Evaluation Report 2005. : Government of Kenya: Ministry of Planning and National Development: Accessible from Bondo District Resource Centre.

NACC (2006). Kenya HIV/AIDS Data Booklet 2006. National AIDS Control Council: Republic of Kenya.

Nyambedha, E., Wandibba, S., \& Aagaard-Hansen, J. (2003). Changing patterns of orphan care due to the HIV epidemic in Western Kenya. Social Science E' Medicine, 57(2), 301-311. 
O'Kane, C. (2008). The development of participatory techniques: Facilitating children's views about decisions which affect them. In P. Christensen, \& A. James (Eds.), Research with children: Perspectives and practices (pp. 125-155). (Second ed.). New York: Routledge.

Rifkin, S., \& Pridmore, P. (2001). Partners in planning. Information, participation and empowerment. London: TALC/Macmillan Education Ltd.

Robson, E. (2000). Invisible carers: Young people in Zimbabwe's home-based health care. Area, 32, 59-69.

Robson, E. (2004). Hidden child workers: Young carers in Zimbabwe. Antipode, 36(2), 227-248.

Robson, E., \& Ansell, N. (2000). Young carers in Southern Africa: Exploring stories from Zimbabwean secondary school students. In S. Holloway, \& G. Valentine (Eds.), Children's Geograpahies: Playing, Living, Learning (pp. 174-193). London: Routledge.

Robson, E., Ansell, N., Huber, U., Gould, W., \& van Blerk, L. (2006). Young caregivers in the context of the HIV/AIDS pandemic in sub-Saharan Africa. Population, Space and Place, 12, 93-111.

Save the Children (2010). Child carers: Child-led research with children who are carers. Pretoria: Save the Children UK, Southern Africa. url. http://www.savethechildren. org.uk/en/docs/Child_Carer_Report_English.pdf retrieved on 15/02/2011.

Skovdal, M. (2010a). Agency, resilience and the psychosocial well-being of caregiving children: Experiences from Western Kenya. In S. Evers, C. Notermans, \& E. van
Ommering (Eds.), Not Just a Victim: The Child as Catalyst and Witness of Contemporary Africa. Leiden: Brill.

Skovdal, M. (2010b). Children caring for their 'caregivers': Exploring the caring arrangements in households affected by AIDS in Western Kenya. AIDS Care, 22(1), 96-103.

Skovdal, M. (2010c). Community relations and child-led microfinance: A case study of caregiving children in Western Kenya. AIDS Care, 22(Supplement 2), 1652-1661.

Skovdal, M., \& Andreouli, E. (2010). Using Identity and Recognition as a framework to understand and promote the resilience of Caregiving Children in Western Kenya. Journal of Social Policy, 40(4), doi:10.1017/S0047279410000693.

Skovdal, M. \& Ogutu, V. (2009). "I washed and fed my mother before going to school": Understanding the psychosocial well-being of children providing chronic care for adults affected by HIV/AIDS in Western Kenya. Globalisation and Health, 5, 8, doi:10.1186/17448603-5-8.

Skovdal, M., Ogutu, V., Aoro, C., \& Campbell, C. (2009). Young carers as social actors: Coping strategies of children caring for ailing or ageing guardians in Western Kenya. Social Science \& Medicine, 69(4), 587-595.

Wang, C. (2006). Youth participation in photovoice as a strategy for community change. In B. Checkoway, \& L. M. Gutiérrez (Eds.), Youth Participation and community change (pp. 147-161). Binghamton, NY: Haworth Press, Inc.

Wang, C., \& Burris, M. (1997). Photovoice: Concept, methodology, and use for participatory needs assessment. Health Education \& Behaviour, 24(3), 369-387. 